\title{
Somatic Embryogenesis from Cell Suspension Cultures of Taranoki (Aralia elata)
}

\author{
Md Ziaul Karim***, Shinso YoKota**, Md. Mahabubur Rahman***, \\ Junji EIZAWA**, Yasuno SAITO**, Mustafa Abul Kalam AzAD**, \\ Futoshi Ishiguri**, Kazuya IIzUKA** and Nobuo YoshizawA** \\ * United Graduate School of Agricultural Science, Tokyo University of Agriculture and Technology, \\ Fuchu, Tokyo 183-8509, Japan \\ ** Faculty of Agriculture, Utsunomiya University, Utsunomiya 321-8505, Japan
}

(Received August 24, 2007)

\begin{abstract}
The objective of this study was to increase the formation rate of embryos from suspension cultures of Taranoki (Aralia elata). The suspension cultures were prepared from leaf-derived calli. Of the various culture durations, 30 days of culture yielded the best growth of cell suspension cultures in a BT liquid medium supplemented with 2,4-D. Somatic embryogenesis has never been observed without the addition of exogenous plant growth regulators (PGRs). The highest percentage of somatic embryo formation (93.3\%) was observed in a BT liquid medium supplemented with $1.0 \mu \mathrm{M}$ BAP $+5.0 \mu \mathrm{M}$ 2,4-D. The PGR-free semi-solid BT medium showed the highest regeneration frequency of cotyledonary-shaped embryos $(100 \%)$.
\end{abstract}

Keywords : Aralia elata, embryo, embryogenesis, suspension cultures

\section{INTRODUCTION}

Taranoki, Aralia elata, is a small deciduous tree. This species is distributed in Japan, Korea, and China. The fresh buds of Taranoki are edible, flavorful, and nutritious (Kira, 1998). In addition, the root and bark of the tree are also used for traditional folk medicine (Sim et al., 2005).

For the clonal propagation of Taranoki, root cuttings have been used (Kira, 1998). In addition, micropropagation of this species using tissue culture techniques has been developed by many researchers (Amemiya et al., 1992; Jhang et al., 1994; Yoshizawa et al., 1994; Moon and Youn, 1999; Furuya and Hosoki, 2004).

There are several reports on somatic embryogenesis in Taranoki (Amemiya et al., 1992; Jhang et al., 1994; Moon and Youn, 1999; Furuya and Hosoki, 2004). Amemiya et al. (1992) reported that, in Taranoki, somatic embryos from petiole-derived calli were obtained in an MS medium supplemented with a 2-to-5-times concentration of $\mathrm{FeSO}_{4} \cdot 7 \mathrm{H}_{2} \mathrm{O}+\mathrm{Na}_{2}$ EDTA. Jhang et al. (1994) also reported that embryogenic calli were formed from petiole-derived suspension cultures in an MS medium containing 2,4-D and TDZ. They also found that a quarter-strength MS medium was effective for increasing the number of somatic embryos. Moon and Youn (1999) mentioned that BAP with 2,4-D was suitable for the initiation of somatic embryos in Taranoki. Furuya and Hosoki (2004) also reported that somatic embryogenesis was observed in the root-derived calli of Taranoki formed in an MS medium supplemented with more than $0.5 \mathrm{mg} / 1(2.26 \mu \mathrm{M})$ 2,4-D. However, more

Corresponding author: Nobuo Yoshizawa, fax : +81-28-649-5544, e-mail : nobuoy@cc.utsunomiya-u.ac.jp 


\section{Z. KARIM ET AL.}

information to increase the formation rate of embryos in Taranoki is needed.

In the present study, to increase the formation rate of embryos in Taranoki, somatic embryogenesis from suspension cultures were investigated.

\section{MATERIALS AND METHODS}

For the suspension culture, calli were induced from mature Taranoki leaves growing in the field according to a method established by Karim et al. (2007). Cell suspension cultures were initiated by placing $1 \mathrm{~g}$ fresh weight of leaf-derived friable calli, which had been induced in an BT medium (Chalupa, 1984) with $5.0 \mu \mathrm{M}$ 2,4-D, into a $40 \mathrm{ml}$ liquid BT medium in a $100 \mathrm{ml}$ Erlenmeyer flask. For the induction of cell suspensions, different concentrations (2.0, 5.0, and 10.0 $\mu \mathrm{M})$ of auxin (2,4-D or NAA) or cytokinin (BAP) were used. The cultures were incubated under light on a rotary shaker at $100 \mathrm{rpm}$ to allow the callus to disaggregate. They were subcultured every 2 weeks with the addition of $5 \mathrm{ml}$ to $40 \mathrm{ml}$ of a fresh medium in a $100 \mathrm{ml}$ Erlenmeyer flask. The culture was performed at $25 \pm 1{ }^{\circ} \mathrm{C}$ under illumination of cool-white florescent lamps with a light intensity of $50 \mu \mathrm{mol} \mathrm{m}^{-2} \mathrm{~s}^{-1}$ for a $16 \mathrm{~h}$ photoperiod during agitation $(100 \mathrm{rpm})$. To determine the fresh mass, cell clusters were collected on a filter paper, transferred onto pre-weighted aluminum foil, and immediately weighed, and the weighted cells were placed overnight in an oven at $105^{\circ} \mathrm{C}$ for the determination of dry weight.

To allow plant regeneration, 20 mature cotyledonary-shaped embryos ( $2 \mathrm{~mm}$ in length) were transferred by forceps into Petri dishes containing $40 \mathrm{ml}$ of solidified media supplemented with different concentrations $(0.25,0.50,0.75$, and $1.00 \mu \mathrm{M})$ of BAP or without any PGRs.

\section{RESULTS}

After 8 weeks of culture, regenerable and yellow-green calli were obtained from leaf explants cultured in an BT medium with 5.0 $\mu \mathrm{M}$ 2,4-D (Fig. 1). In the present study, these calli were used as the starting material for initiating the suspension cultures. Table 1 shows changes in the weight of suspended cells during culture in a liquid BT medium supplemented with different concentrations and types of PGR. When the suspension cultures were subcultured in the new medium supplemented with the same PGR, they showed active growth browning. Among different concentrations and types of PGR, $5.0 \mu \mathrm{M}$ 2,4-D showed the best response for the initiation of cell suspension. A very good result was obtained in $5.0 \mu \mathrm{M}$ NAA. Different concentrations of BAP showed low performance for the initiation of cell suspension cultures from leaf-derived calli. In all media used in this study, the weight of suspended cells increased with increasing the duration

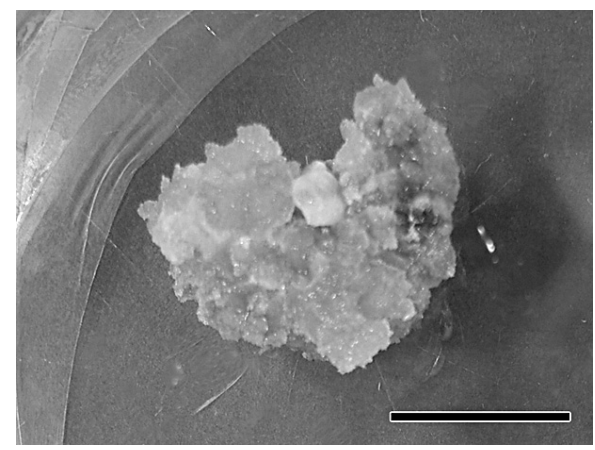

Fig. 1 Leaf-derived calli cultured in an BT medium with 5.0 $\mu \mathrm{M}$ 2,4-D. Note: Scale bar $=1 \mathrm{~cm}$. 
of culture up to 30 days. The highest fresh and dry weights were observed in a BT medium supplemented with $5.0 \mu \mathrm{M} 2,4-\mathrm{D}$, and the weights were $2.0 \pm 0.3 \mathrm{~g}$ and $0.6 \pm 0.8 \mathrm{~g}$, respectively (Tukey's multiple comparison test, $5 \%$ level).

The formation and maturation of somatic embryos in cell suspension cultures are shown in Table 2. After 4 weeks of culture incubation, many small cell clumps growing vigorously were produced from the adaptive callus and continuously released into the medium. The addition of BAP with 2,4-D produced a higher frequency of somatic embryos than 2,4-D or NAA alone. The highest frequency of somatic embryo formation (93.3\%) was observed in combination of $1.0 \mu \mathrm{M}$ $\mathrm{BAP}+5.0 \mu \mathrm{M}$ 2,4-D (Fig. 2A). Globular- to heart-shaped embryos prior to the cotyledonary stage were observed. They were observed in the third subculture (Fig. 2 B and C). The embryos formed a semicompact aggregate at the globular stage, which varied from creamy white to light green and sometimes to translucent or dark green. Torpedo and cotyledonary embryos were observed in a BT medium supplemented with $1.0 \mu \mathrm{M} \mathrm{BAP}+5.0 \mu \mathrm{M} 2,4-\mathrm{D}$ after 4 to 5 weeks of subculture (Fig. 2D). At the cotyledonary stage, embryos developed as green, creamy-white, opaque-white, and translucent structures with one, two, or even more cotyledons, which could be fused into a cup shape.

The effects of PGR on plant regeneration from the cotyledonary stage of somatic embryos are shown in Table 3. The PGR-free medium showed the highest result of plant regeneration, and the frequency was $100 \%$ (Fig. 3A-C). Among the different concentrations, $0.25 \mu \mathrm{M}$ BAP showed an effective result with a regeneration frequency of $63.3 \%$. On the other hand, $0.50,0.75$, and 1.00 $\mu \mathrm{M}$ BAP failed to regenerate any normal plantlets. In this case, they produced malformed plantlets or directly produced calli from the adjacent side of the medium (Fig. 3D-F).

Table 1 Growth of cells in a liquid BT medium in cultures of various durations.

\begin{tabular}{|c|c|c|c|c|c|c|c|}
\hline \multirow{2}{*}{ PGR } & \multirow{2}{*}{$(\mu \mathrm{M})$} & \multicolumn{3}{|c|}{ Fresh weight of suspended cells (g) } & \multicolumn{3}{|c|}{ Dry weight of suspended cells (g) } \\
\hline & & After 10 days & After 20 days & After 30 days & After 10 days & After 20 days & After 30 days \\
\hline \multirow{3}{*}{ 2,4-D } & 2.0 & $0.8 \pm 0.3 b$ & $1.0 \pm 0.4 \mathrm{a}$ & $1.2 \pm 0.2 \mathrm{a}$ & $0.3 \pm 0.3 b$ & $0.3 \pm 0.9 \mathrm{~b}$ & $0.4 \pm 0.2 b$ \\
\hline & 5.0 & $1.2 \pm 0.3 \mathrm{a}$ & $1.5 \pm 0.3 \mathrm{a}$ & $2.0 \pm 0.3 \mathrm{a}$ & $0.4 \pm 0.5 \mathrm{a}$ & $0.5 \pm 0.6 \mathrm{a}$ & $0.6 \pm 0.8 \mathrm{a}$ \\
\hline & 10.0 & $0.6 \pm 0.5 \mathrm{c}$ & $0.8 \pm 0.4 \mathrm{~b}$ & $1.0 \pm 0.8 \mathrm{~b}$ & $0.2 \pm 0.7 \mathrm{c}$ & $0.2 \pm 0.2 \mathrm{c}$ & $0.3 \pm 0.2 \mathrm{c}$ \\
\hline \multirow{3}{*}{ NAA } & 2.0 & $0.5 \pm 0.7 \mathrm{c}$ & $0.8 \pm 0.6 \mathrm{~b}$ & $0.9 \pm 0.7 b$ & $0.2 \pm 0.2 \mathrm{c}$ & $0.3 \pm 0.3 \mathrm{c}$ & $0.3 \pm 0.2 \mathrm{c}$ \\
\hline & 5.0 & $0.6 \pm 0.5 \mathrm{c}$ & $0.9 \pm 0.9 b$ & $1.0 \pm 0.1 \mathrm{~b}$ & $0.3 \pm 0.5 b$ & $0.3 \pm 0.4 \mathrm{~d}$ & $0.4 \pm 0.2 b$ \\
\hline & 10.0 & $0.4 \pm 0.3 \mathrm{~d}$ & $0.7 \pm 0.5 \mathrm{c}$ & $0.9 \pm 0.4 \mathrm{~b}$ & $0.2 \pm 0.9 \mathrm{~d}$ & $0.2 \pm 0.2 \mathrm{c}$ & $0.3 \pm 0.4 \mathrm{~d}$ \\
\hline \multirow{3}{*}{ BAP } & 2.0 & $0.4 \pm 0.7 \mathrm{~d}$ & $0.5 \pm 0.1 \mathrm{~d}$ & $0.7 \pm 0.3 \mathrm{c}$ & $0.1 \pm 0.1 \mathrm{~d}$ & $0.2 \pm 0.4 \mathrm{c}$ & $0.3 \pm 0.3 \mathrm{~d}$ \\
\hline & 5.0 & $0.5 \pm 0.2 \mathrm{c}$ & $0.8 \pm 0.3 b$ & $0.9 \pm 0.2 b$ & $0.2 \pm 0.7 \mathrm{~d}$ & $0.2 \pm 0.7 \mathrm{c}$ & $0.3 \pm 0.5 \mathrm{c}$ \\
\hline & 10.0 & $0.4 \pm 0.2 \mathrm{~d}$ & $0.5 \pm 0.3 \mathrm{~d}$ & $0.6 \pm 0.3 \mathrm{c}$ & $0.1 \pm 0.3 \mathrm{~d}$ & $0.1 \pm 0.1 \mathrm{~d}$ & $0.2 \pm 0.2 \mathrm{~d}$ \\
\hline
\end{tabular}

Values represent means \pm standard errors of 5 replicates per treatment in three repeated experiments. Means followed by the same letter are not significantly different by Turky's multiple comparison test at 0.05 probability level.

Table 2 Formation and maturation of somatic embryos from leaf-derived cell suspension cultures.

\begin{tabular}{ccc}
\hline \multicolumn{2}{c}{ PGR $(\mu \mathrm{M})$} & $\begin{array}{c}\text { Somatic embryo formation } \\
\text { per culture }(\%)\end{array}$ \\
\hline \multirow{3}{*}{$2,4-\mathrm{D}$} & 2.0 & 30.0 \\
& 5.0 & 53.3 \\
& 10.0 & 23.3 \\
\hline \multirow{3}{*}{ NAA } & 2.0 & 26.7 \\
& 5.0 & 43.3 \\
BAP $+2,4-\mathrm{D}$ & 10.0 & 20.0 \\
& $1.0+2.0$ & 60.0 \\
& $1.0+5.0$ & 93.3 \\
\hline
\end{tabular}



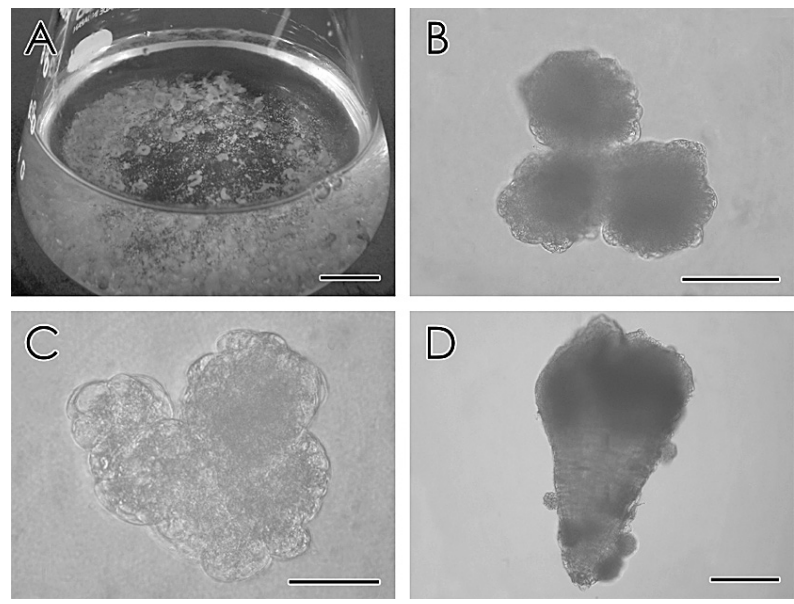

Fig. 2 Development and maturation of somatic embryos.

Note: A, development of somatic embryos; B, globular-shaped embryos; C, heart-shaped embryo; $\mathrm{D}$, torpedo-shaped embryo; Basal medium, liquid $\mathrm{BT}$ medium with $1.0 \mu \mathrm{M} \mathrm{BAP}+5.0 \mu \mathrm{M} 2,4-\mathrm{D}$; scale bar, $\mathrm{A}=1 \mathrm{~cm}, \mathrm{~B}-\mathrm{D}=100 \mu \mathrm{M}$.

Table 3 Plantlet regeneration from embryos in the cotyledonary stage.

\begin{tabular}{cccc}
\hline \multicolumn{2}{c}{ Cytokinin $(\mu \mathrm{M})$} & Plant regeneration (\%) & Callusing \\
\hline \multicolumn{2}{c}{ Free } & 100.0 & - \\
\multirow{4}{*}{ BAP } & 0.25 & 63.3 & - \\
& 0.50 & 0.0 & + \\
& 0.75 & 0.0 & + \\
& 1.00 & 0.0 & + \\
\hline
\end{tabular}

Symbols of "-" and "+" indicates no response or callusing, respectively.

\section{DISCUSSION}

Ribas et al. (2000) found that a low concentration of cytokinin and a high concentration of auxin were effective for the induction and development of somatic embryos in A. polyneuron. Kao and Michayluk (1981) reported that a combination of 2,4-D or NAA with cytokinin was essential for the induction of somatic embryos in Alfalia. In Taranoki, Moon and Youn (1999) reported that BAP with 2,4-D was suitable for the initiation of somatic embryos. In the present study, as shown in Table 2, the addition of BAP with 2,4-D produced a higher frequency of somatic embryos than 2,4-D or NAA alone. Therefore, a balance of BAP and 2,4-D was assumed to be necessary for the induction of somatic embryogenesis in Taranoki.

The germination of somatic embryos can occur only when the embryos are mature enough to have functional shoots and root apices capable of meristematic growth. Several reports on plant regeneration from somatic embryos in Taranoki have been published (Amemiya et al., 1992; Jhang et al., 1994; Moon and Youn, 1999; Furuya and Hosoki, 2004). Jhang et al. (1994) reported that normal plantlets $(86 \%)$ were regenerated from mature somatic embryos in an MS basal medium and that $50 \%$ of them survived when transplanted to vermiculite in a greenhouse. Moon and Youn (1999) noted that normal plant regeneration was achieved when the embryos were recultured in an MS basal medium (with $14 \%$ frequency) and in MS with $0.58 \mu \mathrm{M} \mathrm{GA}_{3}$ (with $11 \%$ frequency). In the present study, as shown in Table 3, plant regeneration was observed only in a PGR-free 

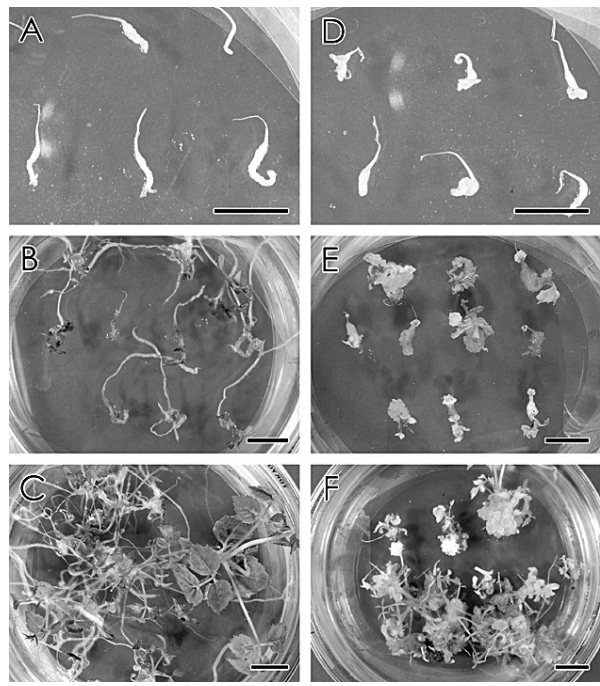

Fig. 3 Plant regeneration from somatic embryos.

Note: A-C, plantlet regeneration from the cotyledonary stage embryos in a BT semi-solid medium without any PGRs after 1 week (A), 3 weeks (B), and 6 weeks (C) of culture; D-F, malformed plantlets with calli regenerated from somatic embryos in a BT semi-solid medium containing $1.0 \mu \mathrm{M}$ BAP after 1 week (D), 3 weeks (E), and 6 weeks (F) of culture; scale bar $=1 \mathrm{~cm}$.

medium and with a low concentration $(0.25 \mu \mathrm{M})$ of BAP. The PGR-free medium gave the highest $(100 \%)$ regeneration frequency (Table 3$)$. This plant regeneration percentage from embryos in the cotyledonary stage is higher than that at other pre-cotyledonary stages, as has been proved in other studies (Jhang et al., 1994; Moon and Youn, 1999). In addition, the survival rate at the acclimatization of embryo-derived plants was $60 \%$ (data not shown).

In conclusion, the established procedure may be useful for the mass propagation of clonal plants of Taranoki because the percentage of plant regeneration from embryos and the survival rate at acclimatization were relatively high.

\section{REFERENCES}

Amemiya, K., Fujiki, T., Hyuga, S. 1992. Mass propagation by tissue culture in Japanese Angelica tree (Aralia elata S.). Annual Report of Yamanashi Agricultural Experiment Station, 5: 11-22

Chalupa, V. 1984. In vitro propagation of Oak (Quercus robur L.) and Linden (Tilia cordata Mill.). Biol. Plant. 26: $374-377$.

Furuya, H., Hosoki, T. 2004. Adventitious shoot formation, embryogenesis and plantlet regeneration from in vitro-cultured root tissue of Japanese Angelica tree (Aralia elata Seemann). Hort. Res. Japan 3: 355-360.

Jhang, H. H., Park, C. H., Lee, Y. S., Shin, Y. B. 1994. Somatic embryogenesis and plant regeneration in suspension cultures of Aralia elata S. Korean J. Plant Tissue Culture 21: 167-171.

Kao, K. N., Michayluk, M. R. 1981. Embryoid formation in alfalfa cell suspension cultures from different plants. In Vitro 17: 645-648.

Karim, M. Z., Yokota, S., Rahman, M. M., Eizawa, J., Saito, Y., Azad, M. A. K., Ishiguri, F., Iizuka, K., Yoshizawa, N. 2007. Micropropagation of plantlets through callus in Taranoki (Aralia elata). Bull Utsunomiya Univ. For. 43: 171-176.

Kira, K. 1998. Tokuyouju no saibaigijutu. In "Ringyougijutsu Handobukku” (ed. by Forestry agency), National Forestry Extension Association in Japan, Tokyo, p 1829-1885. 


\section{Z. KARIM ET AL.}

Moon, H. K., Youn, Y. 1999. Somatic embryogenesis from winter buds of 10-year-old Aralia elata. In "Somatic Embryogenesis in Woody Plants, vol 5" (ed. by Jain, S. M., Gupta, P. K., Newton, R. J.), Kluwer Academic Publishers, Dordrecht, Boston, London, p 129-134.

Ribas, L. L. F., Guerra, M. P., Zanette, F., Kulchetscki, L. 2000. Somatic embryogenesis in Aspidosperma polyneuron Mull. Arg. In "Somatic Embryogenesis in Woody Plants, vol 6" (ed. by Jain, S. M., Gupta, P. K., Newton, R. J.), Kluwer Academic Publishers, Dordrecht, Boston, London, p 509-537.

Sim, J. S., Zhao, H. L., Li, D. W., Cho, S. Y., Jeong, C. S., Lee, E. B., Kim, Y. S. $2005 . \quad$ Effects of saponins from the root bark of Aralia elata on the transport of chondroitin sulfate in Caco-2 cell monolayers and rates. Biol. Pharm. Bull. 28: 1043-1048.

Yoshizawa, N., Shimizu, H., Wakita, Y., Yokota, S., Idei, T. 1994. Formation of adventitious roots from callus cultures of Taranoki (Aralia elata Seem). Bull. Utsunomiya Univ. For. 30: 19-26. 